\title{
A INVENÇÃO DA VERDADE
}

01 ímpio José Pimenta Neto*

RESUMO:

Este artigo consiste numa sintese da meditação sobre o conhecimento a partir do pensamento de Friederich Nietzsche e do ciclo narrativo José e seus irmãos, de Thomas Mann, visando explicitar as determinações reciprocas entre saber e vida e estabelecer as conseqüências de tal empreendimento no tocante à construção da verdade.

PALAVRAS-CHAVE: Conhecimento, Vida, Narrativa, Racionalidade.

0 conjunto de problemas que constitui o escopo de nosso estudo pode ser anunciado numa formulação relativamente simples: trata-se da meditação que visa estabelecer as condições dę validade do conhecimento. As margens que circunscreveram essa temática ao longo de séculos foram fixadas com base numa espécie de estrita observância teórica que conferia a determinados hábitos de pensamento 0 poder de decidir em absoluto a respeito da pertinência de qualquer consideração feita sobre as matérias sujeitas à sua jurisdição. Importavam como critério último para o debate sobre o saber as justificativas de ordem fundacional -, isto é: qualquer juízo ou proferimento valia como conhecimento em função direta das garantias teórico-ontológicas por ele oferecidas. A intenção de todos os que se orientaram por esta configuração da reflexão sobre o conhecimento era, portanto, definir parâmetros universais e necessários para o encaminhamento do problema do valor do saber.

0 tratamento desse assunto recebeu uma inflexão extremamente peculiar a partir da filosofia de Friedrich Nietzsche. Reconhecendo o saber em suas múltiplas formas como fruto de estratégias precisas a favor da presença dos 


\section{EM TE्EG}

Belo Horizonte, V. I, p. I - 144, Dez. 1997

homens no mundo, o filósofo ensina a ler, na linguagem e em seus usos, seu sentido vital - com o qual interage, a modo de um sintoma, qualquer eventual sentido epistemológico a elas agregado. A exigência de salvaguardas fundacionais para o conhecimento mostra para ele medo e fraqueza. Em contrapartida, a proposta de um conhecimento cuja tônica seja a alegria, mesmo em face dos maiores perigos e adversidades, mostra para ele força e saúde.

0 ciclo narrativo José e seus irmãos, de Thomas Mann, encontra-se, a nosso ver, constitutivamente vinculado a uma perspectiva semelhante acerca do conhecimento. Realização de maturidade de um artista notável, ombreia com a obra nietzscheana na demonstração de possibilidades de saber cujo principal compromisso é com a excelência no viver. A narração da trajetória de José do Egito por Mann franqueia para seu leitor o tema da travessia até o super-homem, cultivado por Nietzsche como ponto alto de sua filosofia. Foi a partir dessa intuição ou associação primitiva que se inıciou a elaboração desta tese.

A principal tarefa em jogo demandou, assim, um duplo movimento. Competia dissociar as questões relativas ao conhecimento do marco reflexivo hegemônico na filosofia para, só então, fazer incidir sobre elas a ótica delineada acima, tributária das idéias de Nietzsche e da narrativa manniana. Além disto, uma aliança entre o saber e a vida, na qual se manifestasse uma apreciação reciprocamente favorável de ambos, exigia a inscrição do trabalho num registro distinto daquele que fora previamente posto de lado. Embora a enunciação de seus conteúdos seja marcada com cores filosóficas, ela pertence, por força de seu conteúdo, ao território da crítica da cultura nomeado comparativismo literário.

Essas colocações preliminares situam e esclarecem o plano geral da investigação. Sua elaboração cumpriu três etapas interdependentes de investigação, versando sobre o cosmos, o logos e a verdade. A primeira fornece uma espécie de bastidor mais abrangente de toda a meditação; a segunda se apropria dos elementos obtidos na anterior, transcrevendo-os conforme os termos e as pautas próprias da ficção narrativa; a terceira, por fim, deriva das relações entre as demais as conseqüências possíveis a propósito do tema da verdade. Há, então, algo como a convergência das discussões sobre o cosmos e o logos - o que inclui 
também sua mútua determinação - em direção ao tópico da verdade.

Quanto ao cosmos, impôs-se de início a realização de uma crítica da metafísica da permanência. A partir dos autores, questionou-se o conceito de identidade e suas implicações valorativas. Emergiu daí a proposta de um pluralismo cosmológico, em nome do qual a leitura do mundo ganha em vigor e qualidade. No lugar da fixidez proporcionada por um pensamento comprometido com a busca de certeza por seus cultores, propõe-se a eterna circulação de forças com as quais é possível lidar de modo afirmativo e desassombrado. Para um pensamento grave e cauteloso, a contrapartida de uma especulação arejada e disposta a desafios.

Uma vez que a especulação cosmológica liberou a produção do saber do ônus da certeza absoluta, era pertinente avançar a meditação até o estudo de outras potencialidades da palavra. Se a significação do discurso tornou-se irredutivel a um cálculo clássico de sentido, ganhava interesse a configuração de uma nova chave de leitura para os usos da linguagem. É este o principal ponto de articulação da narrativa e da narração no corpo do texto. A composição de uma poética da narrativa balizada pelo afirmativo nietzscheano e pela sintaxe lunar de Mann explicita um caminho efetivo para a construção do saber e para a reflexão sobre ele - caminho percorrido pelos próprios autores em seus respectivos textos. Deve-se acrescentar que a análise da narrativa em torno de José do Egito desdobrou-se em duas outras frentes. De uma parte, ela facultou o reconhecimento de um modo de avaliar o mundo e os homens francamente afirmativo. De outro, ela trouxe à luz o personagem como um tipo modelar e extraordinário de humanidade, compatível com a criação nietzscheana do super-homem.

Conforme mencionado, o estudo da narração permitia que a própria atividade de produção de conhecimento fosse reavaliada e pensada em moldes diferentes daqueles consagrados pela tradição. A predicação de verdade a um saber poderia prescindir do aval do princípio de correspondência, postulando em seu lugar uma medida, comparativamente, mais compreensiva e flexivel. Para a racionalidade mesma, poderia ser designada uma função antes operacional que normativa. Entendida como um instrumento polivalente, capaz de contribuir na geração de ficções através das quais o mundo seria apropriado afirmativamente, a racionalidade poderia conduzir os homens 


\section{EM TESE}

à invenção da verdade como corolário de sua saúde existencial.

Com isso, a pesquisa da verdade pode revestir-se de novo significado, passando a ser coordenada segundo objetivos nada ortodoxos. A consistência do discurso através do qual tal pesquisa se faz é ainda credencial para sua validação, embora não baste por si só. Ao lado dela, importa conferir a qualidade do discurso em função de sua abertura para o mundo. Arranjo de força entre forças, o conhecimento deve ser capaz de exercer alguma maestria sobre aquilo com que ele se relaciona. Dado seu respaldo numa avaliação afirmativa do cosmos, conta para a avaliação do próprio conhecimento sua intervenção no jogo cósmico da vontade de potência. Pensar a que tipo de vida o saber presta serviço e, simultaneamente, que tipo de vida nele se exprime, é um aspecto decisivo de meditação sobre ele. Se não revogadas, as prescrições de ordem metafísica sobre a justificação do saber são, assim, simplesmente ultrapassadas. Emerge em seu lugar a concepção do saber como meio para a criação de uma verdade compatível com a tessitura cambiante do cosmos em devir. Uma verdade cujo propósito elementar é a celebração da condição a um tempo miserável e sublime da vida humana na terra.

A narrativa estudada parte de uma imagem que, com o correr da narração, adquire o alcance de um emblema completo. Thomas Mann orquestra, através da figura do poço do tempo, uma espécie de visão de mundo, à qual a tese proposta pretendeu se alinhar. Lugar do duradouro e do transitório, ponto de coincidência entre saber e vida, o poço é, portanto, lapidar e ambíguo. É ao lado dele que se contam histórias, é dele que se extrai a provisão para que prossiga a vida. A finitude inexorável dessa, indício de sua impermanência, é lembrada pela água que passa pelo poço. É apropriando-se dessa água que os homens levam adiante sua passagem pelo mundo, do mesmo modo que, apropriando-se dos acontecimentos e das chances disponiveis, podem transformá-1os, por meio da palavra, na condição da afirmação de sua existência. Conversão da morte em alimento da vida, a partir da perspectiva dos que estão vivos: esta é a lição, trágica e alegre, recolhida por nós no poço de Mann e na filosofia de Nietzsche. Se, porventura, tais valores e pontos-de-vista ganharem vigência na cultura, será possível alimentar grandes expectativas a respeito do futuro do conhecimento. 
Belo Horizonte, vol. I, p. 51 - 55, dez. 1997

\section{REFERÊNCIAS BIBLIOGRÁFICAS}

MANN, Thomas. José e seus irmãos. Trad. Agenor Soares de Moura. Rio de Janeiro: Nova Fronteira, 1983. vol. 1,2 e 3 .

NIETZSCHE, Friedrich. O nascimento da tragédia: ou pessimismo e helenismo. Trad. J. Guinsburg. São Paulo: Companhia das Letras, 1992.

NIETZSCHE, Friedrich. Introdução teorética sobre a verdade e a mentira no sentido extra-moral. In: 0 livro do filósofo. Trad. Ana Lobo. Porto Alegre: Rés, $s / d$.

NIETZSCHE, Friedrich. Genealogia da moral: um escrito polêmico. Trad. Paulo César Souza. São Paulo: Brasiliense, 1988.

NIETZSCHE, Friedrich. Más allấ del bien y del mal. Trad. Andrés Sanchez Pascual. Madri: Alianza, 1985.

NIETZSCHE, Friedrich. Ecce homo. Trad. Andrës Sanches. Madrid: Alianza, 1985.

NIETZSCHE, Friedrich. A gaia ciência. Trad. Mário Publiesi, Edson Bini e Norberto de Paula Lima. São Paulo: Hemus, 1981.

NIETZSCHE, Friedrich. La voluntad de poderio. Trad. Aníbal Fouje. Madrid: Edaf, 1981.

PIMENTA NETO, 01 ímpio José. A invenção da verdade. Belo Horizonte: Faculdade de Letras, 1996. 165 p. (Tese, Doutorado em Literatura Comparada). 